\title{
VOLTAGE SAG SENSITIVITY OF INDUSTRIAL VECTOR CONTROLLED INDUCTION MOTOR DRIVES - A COMPARATIVE STUDY
}

\author{
UDC (629.35.12.1:534.83):679.013
}

\section{Milutin Petronijević, Boban Veselić, Nebojša Mitrović, Vojkan Kostić}

University of Niš, Faculty of Electronic Engineering, Republic of Serbia

\begin{abstract}
Sensitivity of adjustable speed drives (ASDs) on voltage sag events represents one of the most challenging problems in modern industrial facilities. In this paper, a comprehensive experimental verification of vector-controlled ASDs is conducted under the most-frequent sag types. The obtained results are faced with static and dynamic requirements in speed and torque controlled applications. Besides influence of DC-link parameters, selection of the applied control method and the controller settings can have crucial impact on performance deterioration. Examined industrial ASDs exhibited voltage sag susceptibility with fault error codes under the deeper voltage sags, while under the voltage sags with residual voltage above undervoltage limit they showed speed degradation.
\end{abstract}

Key words: power quality, voltage sag, adjustable speed drives, field oriented control, comparative study.

\section{INTRODUCTION}

High performance adjustable speed drives (ASDs) with induction motors (IMs) can be used for torque, speed, position or process control in a wide range of installed/rated powers in industry. Precise control, without static error and with pre-programmed dynamic response, is required under declared power supply conditions. However, it is very convenient if ASDs provide not degraded performances in case of short time power line disturbances. Voltage sags (dips) are power quality problems, which are the most expected by the consumers in public power supply networks. This type of voltage disturbance presents a short-duration (half period to 1 minute) voltage reduction, where the usual limits of the remaining voltage are between $10 \%$ and $90 \%$ in rms of the

Received July 10, 2017

Corresponding author: Milutin Petronijević

University of Niš, Faculty of Electronic Engineering, Republic of Serbia

E-mail: milutin.petronijevic@elfak.ni.ac.rs 
nominal voltage [1]. An important requirement regarding uninterrupted operation under power supply disturbances is to study ASDs behaviour when no failure occurs, since performance degradation may arise [2-3].

ASDs voltage sag sensitivity was examined in numerous studies and research papers in recent years, mainly by the basic testing criteria - drive trip/pass. In the experimental study [4], the importance of ASD sensitivity on symmetrical and unsymmetrical voltage sags was confirmed, with the main conclusion that the sag type, the remaining voltage magnitude and the motor load primarily influenced the drive susceptibility, without considering the impact of the control algorithm. Voltage sags with a decrease in the mean value of DC voltage lead to the reduction of the IM available torque [5], while increased DC voltage ripple induces the ripples both in motor torque and currents [6]. For vectorcontrolled drives with field oriented control (FOC) and direct torque control (DTC), the performances degradation is influenced by the characteristics of the internal regulation loop, mostly in terms of current reduction and torque ripple [5], [7-8]. Previous theoretical and experimental studies [5-8] consider the sensitivity of vector-controlled ASDs, while scalar-controlled industrial drives are examined in [4].

The simulation study [9] proposes models of vector-regulated drives for the purpose of analysing the voltage dip effect. The study [10] suggests the use of a simplified model of ASDs obtained on the basis of experimental data, but primarily to investigate the effects of sags onto the input current and DC voltage. The researches [5] and [8] explain the causes and confirm the performance degradation in the case of unsymmetrical voltage sags in the examples of FOC and DTC controlled drives for laboratory-developed control algorithms. Experimental evidence of industrial vector controlled ASDs performance evaluation under voltage sags rarely exists because of a complex procedure of adjusting the drive control parameters and the necessity of using complex equipment for performance verification.

This paper aims to investigate performance deviation of the FOC IM drives in speed control tasks, fed by converters of different manufacturers. The experimental results show significant differences in behaviour of ASDs, depending on the applied control algorithm, but also depending on the power circuit parameters of converters of individual manufacturers. The research indicates potential problems to industry users, but also suggests possible solutions.

The rest of the paper is organized as follows. Section 2 gives a short description of the vector controlled ASDs testing, whereas Section 3 presents consequences of symmetrical and un-symmetrical voltage sags with special attention on control performance deviation. A short description of laboratory setup and ASDs under tests is given in Section 4. The main Section 5 provides the experimental results and their comparison. Finally, the paper ends with some conclusions and references.

\section{Testing OF Vector Controlled ASDS}

IM control schemes can be grouped into two major classes - the first one is scalar and the second one is vector. The scalar schemes allow control of only output voltage frequency and magnitude, while the vector ones enable control of instantaneous voltage, current and flux vectors. This provides a more precise control of motor speed or torque. 
The two most important industrial groups of vector controlled ASDs are field oriented control (FOC) and direct torque control (DTC) of IM drives.

The main idea behind the IM vector control using field orientation is to use the information about flux space vector angular position and amplitude. Depending on the flux phasor choice, there are orientations with respect to the field of the rotor (rotor field oriented - RFO), to the field of the stator (stator field oriented - SFO) or to the air gap flux (magnetizing flux oriented - MFO). These methods are ordered relative to their presence in practical applications. Hence, RFO control schemes are mostly used in industrial frequency converters and therefore subject of interest in this paper.

Voltage sags are generally two-dimensional power supply disturbances that are characterized by the relative value of the residual voltage $h$ (in $\%$ or p.u.) and the duration of the disturbance $\Delta t$. Voltage drops due to transmission system faults affect a wider area of consumers, but on the other hand their duration is short. Propagation of single-phase faults, which are the most frequent short circuit events, leads to the occurrence of multiphase sags depending on the transformer winding connection involved in the power supply path.

The harmonized classification [11-12] implies the boundaries for $h$ from 0.1 to 0.9 p.u., while the time duration $\Delta t$ takes the range of a half period of mains voltage up to 60 seconds. However, there is no fully compliant approach to the classification of the voltage sag that respects the poly-phase nature of the event, residual voltage shape, influence of the phase shift and the point on sag initiation, and other characteristics of the sag itself. The corresponding IEC standards [2-3] and CIGRE/CIRED/UIE joint working group recommendations [13] for three-phase equipment immunity assessment on power supply disturbances preferably suggest unbalanced sags with phase shift (designated as type I and II) and balanced (type III) voltage sags used for three-phase apparatus testing. In Fig. 1 the corresponding phase vectors and values of remaining voltages recommended for three-phase drive testing are shown.

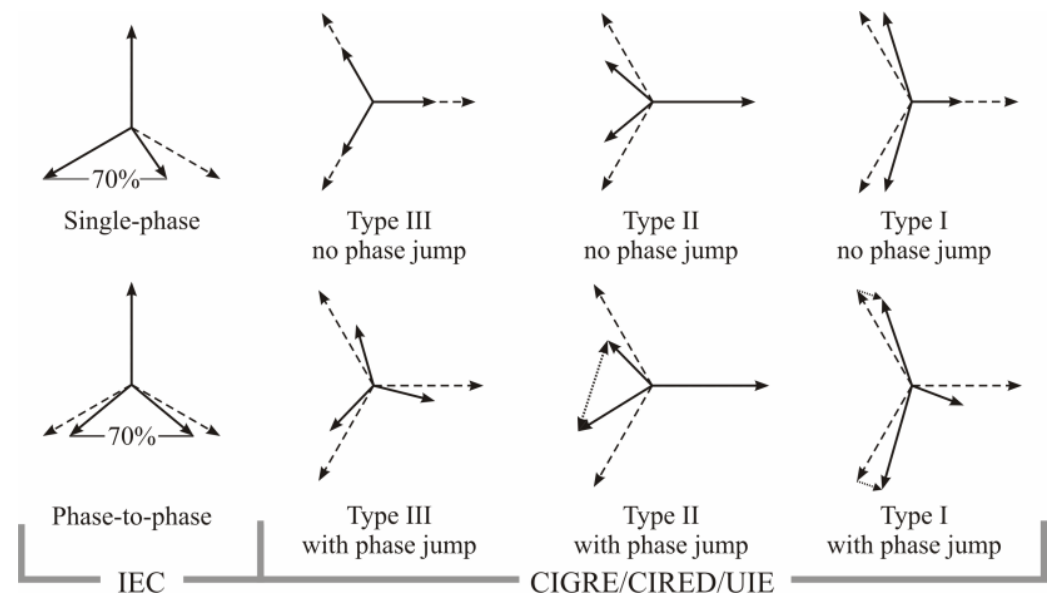

Fig. 1 Basic sag types for drive testing

Table 1 shows widely accepted voltage sag classification [1], which takes into account sag origin and effects of transformer vector group on their propagation in power 
supply networks. During the testing, it is important to provide conditions that relevantly interpret real world voltage sag events, and therefore the obtained test results will be valid and useful for the sensitivity analysis, not only of individual devices, but also of complete facilities.

The data obtained during measurements for industrial sites [14] and measurements in medium and low voltage distribution network [15] indicate several essential facts regarding the voltage drop:

- voltage failure whose residual $h$ voltages are in the range of 70-90\% of the nominal value and lasts up to one second is most often expected at low voltage consumers;

- the vast majority of events that lead to voltage sags occur at low voltage (LV), i.e. at the same voltage level of most industrial consumers;

- single-phase or two-phase voltage sags are significantly more frequent than threephase symmetric voltage sags [16].

The above facts point to the need to test ASDs behaviour mainly in the range of residual voltage $h \geq 70 \%$ and duration $\Delta t \leq 1 \mathrm{~s}$, especially from the aspect of performance degradation in the zone above the disconnection voltage level of the drive under-voltage protection.

The reasons of ASDs disconnection in case of voltage dip event can be classified regarding to the response of the under-voltage and/or the overcurrent protections or due to significant deviations of the controlled variable (process variable/speed/torque) from the set point [17]. Standardized tests of three-phase ASDs involve evaluation of conformity assessment according to the standards [2-3] and recording of sensitivity curves, i.e. determining the time of the inverter's tripping due to the activation of some protection. However, the particular interest is to determine the voltage sag consequences that are not just disconnection, but also possible ASDs performance degradation.

Under symmetrical voltage sags with simultaneous voltage reduction in all phases, the dominant consequence is the reduction of DC voltage proportional to the sag depth. Unsymmetrical voltage sag event can produce voltage reduction, but also an increased DC voltage ripple. The voltage ripple depends on the type of sags, load of the inverter and also on the parameters of the DC circuit and the supply network (values of capacitors and inductance).

Evaluation of equipment under test (EUT) performances taken under the voltage sag effects in accordance to IEC 61000-4-11 and IEC 61000-4-34, classifies the achieved results into four categories in terms of function loss or performance degradation. In case of the highest level of equipment immunity, users can expect equipment normal operation, while in the second and the third category of equipment immunity, performance degradation should be expected with normal state recovery at sag end. In case of the forth category, unrecoverable loss of function or performance degradation can be expected.

Different types of voltage dip generators [18] are used for equipment testing in the field and in laboratory, in a wide range of voltages and power. They are based on a power electronic amplifier, taped transformers or combinations of both. In our experimental investigations we used a tapped autotransformer that directly generates type A and B voltage sags. With a help of inserted transformers with the corresponding vector group connections it is possible to realize all other sag types that include phase shift phenomenon. An important feature of used sag generators is to provide high enough 
inrush currents that appear at sag recovery. This can be obtained easily using a transformer with multi-tap secondary winding or a regulated autotransformer.

Table 1 Voltage sag classification, origin, propagation and complex domain equation according to [1]

\begin{tabular}{|c|c|c|}
\hline $\begin{array}{c}\text { Phasor diagram } \\
\text { (before sag - dashed } \\
\text { line, } \\
\text { during sag - black } \\
\text { line) } \\
\end{array}$ & $\begin{array}{c}\text { Origin and influence of } \\
\text { transformer vector group on } \\
\text { sag propagation }\end{array}$ & $\begin{array}{c}\text { Phase voltages } \\
\text { (complex domain representation) }\end{array}$ \\
\hline 峁 & $\begin{array}{l}\text { Three-phase fault } \\
\mathbf{A} \leftrightarrow Y_{N} y_{n} \leftrightarrow \mathbf{A} \\
\mathbf{A} \leftrightarrow Y y, D d, D z \leftrightarrow \mathbf{A} \\
\mathbf{A} \leftrightarrow Y d, D y, Y z \leftrightarrow \mathbf{A}\end{array}$ & $\begin{array}{l}U_{a}=h U \\
U_{b}=-(1 / 2) h U-j(\sqrt{3} / 2) h U \\
U_{c}=-(1 / 2) h U+j(\sqrt{3} / 2) h U\end{array}$ \\
\hline 总 & $\begin{array}{l}\text { Single-phase fault } \\
\mathbf{B} \leftrightarrow Y_{N} y_{n} \leftrightarrow \mathbf{B} \\
\mathbf{B} \leftrightarrow Y y, D d, D z \leftrightarrow \mathbf{D} \\
\mathbf{B} \leftrightarrow \mathrm{Yd}, \mathrm{Dy}, \mathrm{Yz} \leftrightarrow \mathbf{C}\end{array}$ & $\begin{array}{l}U_{a}=h U \\
U_{b}=-(1 / 2) U-j(\sqrt{3} / 2) U \\
U_{c}=-(1 / 2) U+j(\sqrt{3} / 2) U\end{array}$ \\
\hline 峁 & $\begin{array}{l}\text { Two-phase fault or propagation } \\
\text { of single-phase fault } \\
\mathbf{C} \leftrightarrow \mathrm{Y}_{\mathrm{N}} \mathrm{Y}_{\mathrm{n}} \leftrightarrow \mathbf{C} \\
\mathbf{C} \leftrightarrow \mathrm{Yy}, \mathrm{Dd}, \mathrm{Dz} \leftrightarrow \mathbf{C} \\
\mathbf{C} \leftrightarrow \mathrm{Yd}, \mathrm{Dy}, \mathrm{Yz} \leftrightarrow \mathbf{D}\end{array}$ & $\begin{array}{l}U_{a}=U \\
U_{b}=-(1 / 2) U-j(\sqrt{3} / 2) h U \\
U_{c}=-(1 / 2) U+j(\sqrt{3} / 2) h U\end{array}$ \\
\hline 岂 & $\begin{array}{l}\text { Propagation of single-phase or } \\
\text { two-phase fault } \\
\text { D↔Y } \mathrm{Y}_{\mathrm{N}} \mathrm{y}_{\mathrm{n}} \leftrightarrow \mathbf{D} \\
\mathbf{D} \leftrightarrow \mathrm{Yy}, \mathrm{Dd}, \mathrm{Dz} \leftrightarrow \mathbf{D} \\
\mathbf{D} \leftrightarrow \mathrm{Yd}, \mathrm{Dy}, \mathrm{Yz} \leftrightarrow \mathbf{C}\end{array}$ & $\begin{array}{l}U_{a}=h U \\
U_{b}=-(1 / 2) h U-j(\sqrt{3} / 2) U \\
U_{c}=-(1 / 2) h U+j(\sqrt{3} / 2) U\end{array}$ \\
\hline 战 & $\begin{array}{l}\text { Two-phase to ground fault } \\
\mathbf{E} \leftrightarrow \mathrm{Y}_{\mathrm{N}} \mathrm{y}_{\mathrm{n}} \leftrightarrow \mathbf{E} \\
\mathbf{E} \leftrightarrow \mathrm{Yy}, \mathrm{Dd}, \mathrm{Dz} \leftrightarrow \mathbf{G} \\
\mathbf{E} \leftrightarrow \mathrm{Yd}, \mathrm{Dy}, \mathrm{Yz} \leftrightarrow \mathbf{F}\end{array}$ & $\begin{array}{l}U_{a}=U \\
U_{b}=-(1 / 2) h U-j(\sqrt{3} / 2) h U \\
U_{c}=-(1 / 2) h U+j(\sqrt{3} / 2) h U\end{array}$ \\
\hline 至 & $\begin{array}{l}\text { Propagation of two-phase to } \\
\text { ground fault } \\
\mathbf{F} \leftrightarrow \mathrm{Y}_{\mathrm{N}} \mathrm{y}_{\mathrm{n}} \leftrightarrow \mathbf{F} \\
\mathbf{F} \leftrightarrow \mathrm{Yy}, \mathrm{Dd}, \mathrm{Dz} \leftrightarrow \mathbf{F} \\
\mathbf{F} \leftrightarrow \mathrm{Yd}, \mathrm{Dy}, \mathrm{Yz} \leftrightarrow \mathbf{G}\end{array}$ & $\begin{array}{l}U_{a}=h U \\
U_{b}=-(1 / 2) h U-j[(2+h) / \sqrt{12}] U \\
U_{c}=-(1 / 2) h U+j[(2+h) / \sqrt{12}] U\end{array}$ \\
\hline ڤ્. & $\begin{array}{l}\text { Propagation of two-phase to } \\
\text { ground fault } \\
\mathbf{G} \leftrightarrow \mathrm{Y}_{\mathrm{N}} \mathrm{y} \leftrightarrow \mathbf{G} \\
\mathbf{G} \leftrightarrow \mathrm{Yy}, \mathrm{Dd}, \mathrm{Dz} \leftrightarrow \mathbf{G} \\
\mathbf{G} \leftrightarrow \mathrm{Yd}, \mathrm{Dy}, \mathrm{Yz} \leftrightarrow \mathbf{F}\end{array}$ & $\begin{array}{l}U_{a}=[(2+h) / 3] U \\
U_{b}=-[(2+h) / 6] U-j(\sqrt{3} / 2) h U \\
U_{c}=-[(2+h) / 6] U+j(\sqrt{3} / 2) h U\end{array}$ \\
\hline
\end{tabular}

\section{SENSITIVITY OF VECTOR CONTROLLED ASD}

The reasons for ASDs operation interruption due to the voltage sags can be classified into three groups. The first group represents the sag impact on ASDs control electronics, which also includes the power supply of sensors (encoders, current and voltage sensors, 
...) and digital control circuit of an inverter. Due to the low power requirement for power supply of these systems, this interruption can be easily eliminated by use of external uninterruptible power supply (UPS). The second reason is the activation of under-voltage and/or overcurrent ASDs protection. Voltage source converters usually have a DC voltage measurement used for the soft-charging function, but also for the control algorithm or the activation of some protective functions. Under-voltage protection is usually graded into two levels. The first one is for warning and activation of some functions intended to overcome the reduced DC voltage effect. The most commonly used function is DC-kinetic buffering or controlled ramp-down, where the motor kinetic energy is used to keep the DC voltage at predefined value above the trip limit. The second level of under-voltage protection involves inverter shutdown activation because such DC voltage level cannot provide safe operation of the inverter internal devices, primarily IGBT drivers and protection circuits. In addition, this minimum voltage activates the soft-charging function. This threshold value determines maximum inrush input current of the diode bridge, which occurs at voltage sag recovery. The overcurrent protection of the output IGBT bridge is usually graduated at two levels: the first one allows a short-term (few-seconds) current overload of the output transistors and motors, while the second one reacts for a few $\mu$ s and it is intended for short-circuit current protection of the transistors and motor. It should be noted that the first stage of undervoltage and overcurrent protection can usually be adjusted, while the fast second stage is unavailable for user setup.

In some high performance applications (CNC machines, servo drives, multi-motor drives, some process drives) there are very high requirements in terms of static and dynamic accuracy in control of desired variables. These systems tend to suppress even temporary deviation of the regulated values (torque, speed, position, process quantities) from the references, which can lead to ASDs loss of functionality due to quality deviation of the final product. DC voltage deviation from the nominal mean value or voltage ripple increases the limit of the maximum available motor torque and/or induces additional torque ripple, respectively. The following subsections will briefly illustrate the effects of supply voltage reduction, as well as the influence of un-symmetrical ASDs supply with increased DC voltage oscillation (for more details see [5]).

Generally taking into account input voltage reduction and asymmetry, DC-link voltage can be written as:

$$
v_{D C}(t)=V_{D C}\left(h, P_{\text {load }}\right)+V_{D C 2}\left(h, P_{\text {load }}\right) \cos \left(2 \omega_{i} t+\theta_{2}\right)
$$

where the first term $V_{D C}\left(h, P_{\text {load }}\right)$ represents the mean value of DC voltage that depends on sag type, the remaining voltage sag value $(h)$ and the motor load power $\left(P_{\text {load }}\right)$. Term $V_{D C 2}\left(h, P_{\text {load }}\right)$ denotes the value of the second harmonic of DC voltage (at doubled input angular frequency $\omega_{i}$ ) depending on the parameters of DC filter (values of capacitance $C_{f}$ and inductance $L_{f}$ ), the input sag type and the motor load. Value $V_{D C 2}$ is the nonlinear function of $P_{\text {load }}$ for the given voltage sag type and residual voltage $h$. It can be represented as a look-up table for the sake of analysis. Angle $\theta_{2}$ represents instant (point on input voltage wave) of sag initiation.

As shown in [5], DC voltage (1) in connection with PWM leads to motor stator terminal voltages in synchronous reference frame: 


$$
\begin{aligned}
& u_{d s}(t)=K_{0} \cos \phi+K_{1} \cos \left(2 \omega_{i} t+\theta_{2}+\phi\right)+K_{1} \cos \left(-2 \omega_{i} t-\theta_{2}+\phi\right) \\
& u_{q s}(t)=K_{0} \sin \phi+K_{1} \sin \left(2 \omega_{i} t+\theta_{2}+\phi\right)+K_{1} \sin \left(-2 \omega_{i} t-\theta_{2}+\phi\right)
\end{aligned}
$$

with coefficients given by:

$$
K_{0}=\frac{1}{2} m V_{D C}, K_{1}=\frac{1}{4} m V_{D C 2}
$$

Variable $m$ in above represents the modulation index involved in general representation of PWM modulation signal as

$$
m_{i}(t)=m \cos \left(\omega_{e} t+\varphi_{i}+\phi\right)+m_{0}(t),
$$

where $\omega_{e}$ is the inverter fundamental output angular. Angle $\varphi_{i}$ represents the output voltage phase displacement $\left(\varphi_{i}=\{0,-2 \pi / 3,2 \pi / 3\}\right)$, while the angle $\phi$ indicates initial modulation signal displacement and can be chosen arbitrarily. Signal $m_{0}(\mathrm{t})$ denotes zerosequence modulation component in the carrier based (CB) PWM and also provides direct transformation of the space-vector (SV) PWM into CB PWM.

Voltage balance equations of IM stator circuit required to keep RFO control, written in two-phase $d q$-frame are:

$$
\begin{aligned}
& u_{d s}=R_{s} i_{d s}+\sigma L_{s} \frac{d i_{d s}}{d t}-\omega_{e} \sigma L_{s} i_{q s} \\
& u_{q s}=R_{s} i_{q s}+\sigma L_{s} \frac{d i_{q s}}{d t}+\omega_{e} L_{s} i_{d s}
\end{aligned}
$$

with $\sigma=1-\left(L_{s} L_{r}\right) / M^{2}$ and $L_{s}=M+L_{l s}, L_{r}=M+L_{l r}$. Notations of IM parameters are given in Table 3 in the next section.

Substituting equation (2) into (4), the motor $d q$-current components can be found. In addition to the usual DC components $\left(i_{d s 0}, i_{q s 0}\right)$, the currents contain additional oscillatory components $\left(i_{d s 2}, i_{q s 2}\right)$ :

$$
\begin{aligned}
& i_{d s}=i_{d s 0}+i_{d s 2}=i_{d s 0}+I_{d s 2} \cos \left(2 \omega_{i} t+\delta_{d s}\right) \\
& i_{q s}=i_{q s 0}+i_{q s 2}=i_{q s 0}+I_{q s 2} \cos \left(2 \omega_{i} t+\delta_{q s}\right)
\end{aligned}
$$

where angular positions $\delta_{d s}$ and $\delta_{q s}$ represent current vector displacement related to $d$ - or $q$-axis, respectively.

IM electromagnetic torque can be calculated as:

$$
T_{e}=T_{e 0}+T_{e 2} \cos \left(2 \omega_{i} t+\varphi\left(T_{2}\right)\right)+T_{e 4} \cos \left(4 \omega_{i} t+\varphi\left(T_{2}\right)\right)
$$

where the existence of parasitic torque ripple at doubled and quadrupled input supply angular frequencies can be observed. Angles $\varphi\left(T_{2}\right)$ and $\varphi\left(T_{4}\right)$ depend on motor parameters and loading conditions.

The main consequence of DC voltage ripple is increase of the dominant second harmonic in motor currents and torque according to (5-6), as illustrated in Fig. 2. 

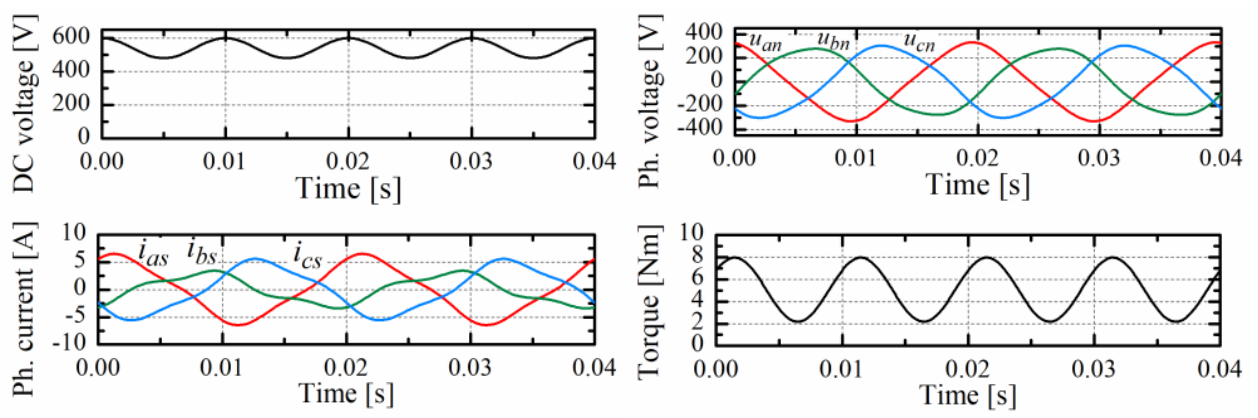

Fig. 2 DC-link voltage, IM stator phase voltages, currents and electromagnetic torque of nominally loaded IM under sag type B with $h=0$ (simulation results for motor parameters from Table 3 and converter ASD2)

These additional variations of the motor current during the voltage sags can trigger overcurrent protection and unwanted disconnection of ASDs. The equations (5-6) are completely valid in the case of scalar $(\mathrm{V} / \mathrm{Hz})$ controlled ASDs without the inner current control loop. However, in case of FOC, being the subject of this paper, the situation is slightly different, as shown in Figure 3. Namely, the internal current loop, according to Fig. 3a, further suppresses the parasitic component $i_{q s 2}\left(i_{d s 2}\right)$ in motor currents and in such a larger bandwidth the suppression will be more efficient as shown in Fig. 3b (for more details see [5]). Therefore, in the vector controlled ASDs, activation of the overcurrent protection initiated by voltage sags is not expected, especially if the current loops are set with a bandwidth that will suppress the second current harmonics.

Reduction of DC voltage exists in case of voltage sag type A and in some other asymmetrical types with line-to-line voltages significantly different from the rated [5]. Reduction of the mean DC voltage component $\left(V_{D C}\right)$ directly results in a proportional reduction in the stator voltage components $\left(v_{d s}\right.$ and $\left.v_{q s}\right)$. Combining the equations (2) and (4) and their replacing in the equation (6) enables us to calculate the maximum available IM torque in the case of RFO control for different stator voltage amplitude. The mentioned limit is known in the literature as the voltage limit and it is of particular importance in the motor operation at speeds close to nominal. An illustration of the effect of the stator voltage amplitude limitation is given in Fig. 4. In addition, this figure illustrates the effect of a different setting of the rotor flux on the boundaries of the voltage limit, which provides the possibility of overcoming the problem of motor torque reduction in case of voltage sags.

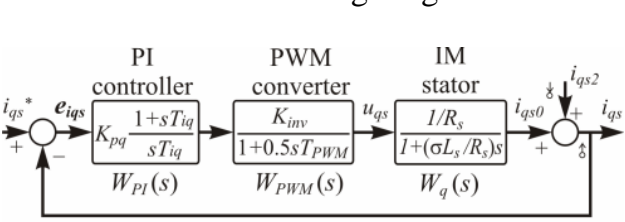

a)

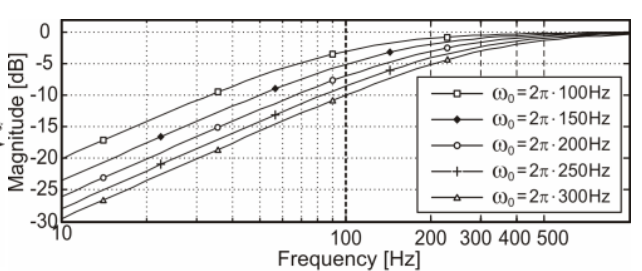

b)

Fig. 3 Voltage ripple effects in RFO vector control drives: a) $q$-axis current control loop b) current loop bandwidth influence on second harmonic component 


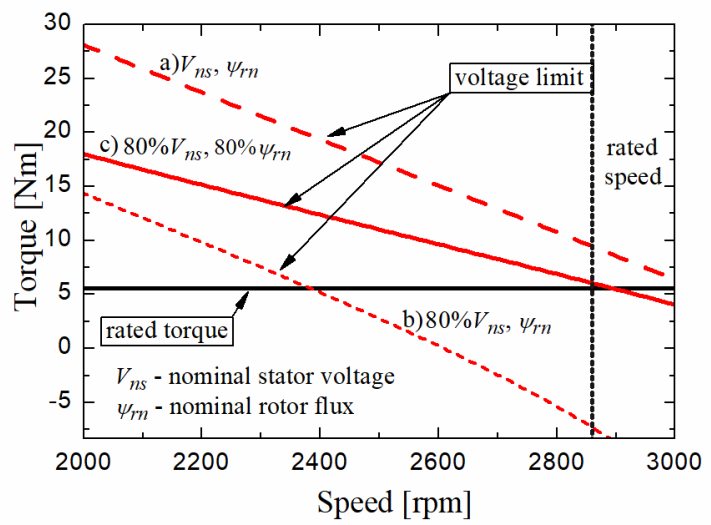

Fig. 4 Effects of voltage reduction on available motor torque: curves a) and b) illustrate the influence of mean voltage reduction; curve c) describes effects of the rotor flux on the maximum available torque

\section{LABORATORY SETUP}

For the purpose of testing and comparisons, converters of three different manufacturers are analysed in this paper, whose the most important parameters are summarized in Table 2. The converters denoted as ASD1 and ASD2 have identical rated power, which is one step oversized compared to the motor power. Topologies of DC circuits in these converters differ: ASD1 converter does not have a choke in the DC circuit - it is already recommended by the manufacturer to use input line reactors (recommended value is $1 \mathrm{mH}$ ). ASD2 is with classical LC filter at diode rectifier output. The third converter, denoted as ASD3, has the power equal to the motor power. It also has a capacitor as an output LC filter.

During the tests, the parameters of all converters are adjusted according to the identical procedure recommended by the manufacturers for vector controlled IM with speed feedback. Using the appropriate factory software and the recommended startup procedure, the current and speed controller parameters are set using default auto-tuning identification, including parameters of the motor equivalent circuit and total inertia. Since all the tested converters have the kinetic buffering as voltage sag ride through option, this feature was turned off during the first set of testing and recording the voltage sag sensitivity curves. These basic converter settings are regarded and denoted as default and accordingly the experiments carried out with this set of parameters carry the same label.

The inverters have been tested for the first basic voltage sags, where in the case of sags $\mathrm{C}$ and $\mathrm{D}$ experiments are limited to propagation of single phase faults, i.e. $h \in[1 / 3,0.9]$. The cause of the shutdown is determined from the alarm list available in the factory software. The main aim of the first group of tests is to determine the immunity, i.e. ASD capability to overcome various types of sags without trip. In the second set of tests, performances of ASDs are evaluated when the converters stay above the trip limit, but the power conditions deviate from the nominal ones. It is in a relationship with the third cause of ASDs disconnection. Experiments were carried out with the main goal to 
comparatively analyse torque deviations and drive speeds for different frequency converter (FC) types.

Table 2 Data of the frequency converters under tests

\begin{tabular}{|c|c|c|c|}
\hline Parameter & ASD1 [19] & ASD2 [20] & ASD3 [21] \\
\hline Rated supply voltage $V_{n}[\mathrm{~V}]$ & $3 \times(380-480)$ & $3 \times(380-500)$ & $3 \times(380-480)$ \\
\hline Supply voltage limits [\%] & $90-110$ & $90-110$ & $85-110$ \\
\hline Nominal output current $I_{n}[\mathrm{~A}]$ & 5.9 & 5.6 & 4.1 \\
\hline Max. cont. output current $I_{\max }[\mathrm{A}]$ & $\begin{array}{l}9.15(30 / 300 \mathrm{~s}) \\
11.8(10 / 60 \mathrm{~s})\end{array}$ & 9 & $6.8(2 \mathrm{~s})$ \\
\hline Under-voltage protection $V_{d c m i n}[\mathrm{~V}]$ & 330 & 373 & 430 \\
\hline Over-voltage protection $V_{d c \max }[\mathrm{V}]$ & 840 & 855 & NA \\
\hline Short-circuit protection $I_{s c}[\mathrm{~A}]$ & NA & NA & 12.5 \\
\hline DC link capacitance $C_{f}[\mu \mathrm{F}]$ & $170^{*}$ & 195 & 195 \\
\hline DC link inductance $L_{f}[\mathrm{mH}]$ & -- & $2 \times 3.85$ & -- \\
\hline
\end{tabular}

* estimated value; $\mathrm{NA}$ - not available data.

All experiments were performed at IM1 rated load, i.e. for IM which is loaded with a constant torque. To emulate the load torque, another $2.2 \mathrm{~kW}$ induction motor (denoted as IM2), with a rated speed of $2885 \mathrm{rpm}$, supplied from a torque controlled ASD, is directly coupled with the tested motor. Speed is detected by Euler backward method using quadrature pulses from an encoder with 8192 optical lines. Figure 5 shows a scheme of the experimental plant, supplied from a custom-made voltage sag generator (denoted by TSAG in the figure) based on an autotransformer and a switching network with contactors. The main limitation of the applied switching devices is variable time delay in opening and closing of the main power contacts, with no possibilities for sag initiation at the exact point on wave.

Table 3 Data of induction motor IM1 (per phase)

\begin{tabular}{lclc}
\hline Rated power $P_{n}[\mathrm{~W}]$ & 1500 & Stator leakage inductance $L_{l s}[\mathrm{mH}]$ & 11.8 \\
Rated speed $n_{n}[\mathrm{rpm}]$ & 2855 & Rotor resistance $R_{r}[\Omega]$ & 3.18 \\
Rated stator phase voltage $V_{s n}[\mathrm{~V}]$ & 230 & Rotor leakage inductance $L_{l r}[\mathrm{mH}]$ & 11.8 \\
Rated current $I_{n}[\mathrm{~A}, \mathrm{rms}]$ & 3.20 & Mutual inductance $M[\mathrm{mH}]$ & 441.3 \\
Stator resistance $R_{s}[\Omega]$ & 5.45 & Total moment of inertia $J_{m}\left[\mathrm{kgm}^{2}\right]$ & 0.0035 \\
\hline
\end{tabular}

In order to illustrate possible performance degradation in the case of supply voltage deviation below the declared nominal values and above the trip limits, a set of experiments is performed. In the following experiments, instantaneous values of the input ASDs supply line-to-line voltages $v_{a b}, v_{b c}$ and $v_{c a}$, electromagnetic torque $T_{e}[\mathrm{Nm}]$, actual speed $n[\mathrm{rpm}]$ and motor currents $i_{a}$ and $i_{b}$ are measured. Motor torque $T_{e}$ is an estimated value from ASDs under tests. 


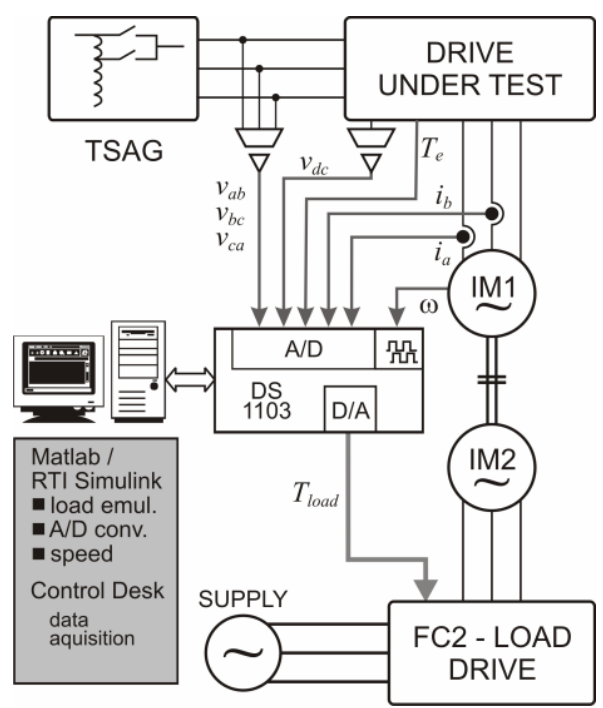

Fig. 5 Block scheme of the experimental setup

\section{EXPERIMENTAL RESULTS AND COMPARISONS}

Three-phase symmetrical voltage sag (type A) impact is analysed first in the case of residual voltage $h$ being in the range from $10 \%$ to $90 \%$ of the nominal input voltage. The aim of the test is to determine the time of the inverter shutdown, i.e. to record the voltage sag sensitivity curves. Due to the different ways of error handling, the moment when the IGBT bridge inverter is turned off (consequently when the motor currents are interrupted) was adopted as the TRIP operating state. This means that there is no electromagnetic torque of IM. It should be noted that the ASD1 converter has a modular control system powered by an independent DC voltage source, while ASD2 and ASD3 controller cards are compactly located inside the device and are internally supplied from the main power supply.

Voltage sag sensitivity curves are shown in Fig. 6a for the three mentioned ASDs with common conclusion about short trip time for smaller values of $h$. If these characteristics are compared to one another, it can be noticed that the vertical part of the curve shows that the shutdown time is within the range of $22 \mathrm{~ms}$ to $25 \mathrm{~ms}$ for sags close to power failure. In the case of sags with higher values of residual voltage, the shutdown time is within the range of $37 \mathrm{~ms}$ to $42 \mathrm{~ms}$ for the characteristic value $h=70 \%$. The differences that exist in the horizontal part of the sensitivity curves are the result of the different settings of the under-voltage protection, as shown in Table 2 . The second reason is the fact that inverter (denoted as ASD1) shows unexpected behavior - the undervoltage trip occurs at the voltage sag recovery. The reason for this is the emergence of additional voltage drops due to diode bridge input inrush current, which is an effect that can be prevented by the built-in DC choke (ASD2) or with input three-phase reactor. ASD1 converter is insensitive to voltage sags type A with $h \geq 78 \%$; converter ASD2 for $h \geq 72 \%$, and ASD3 converter for $h \geq 75 \%$. 

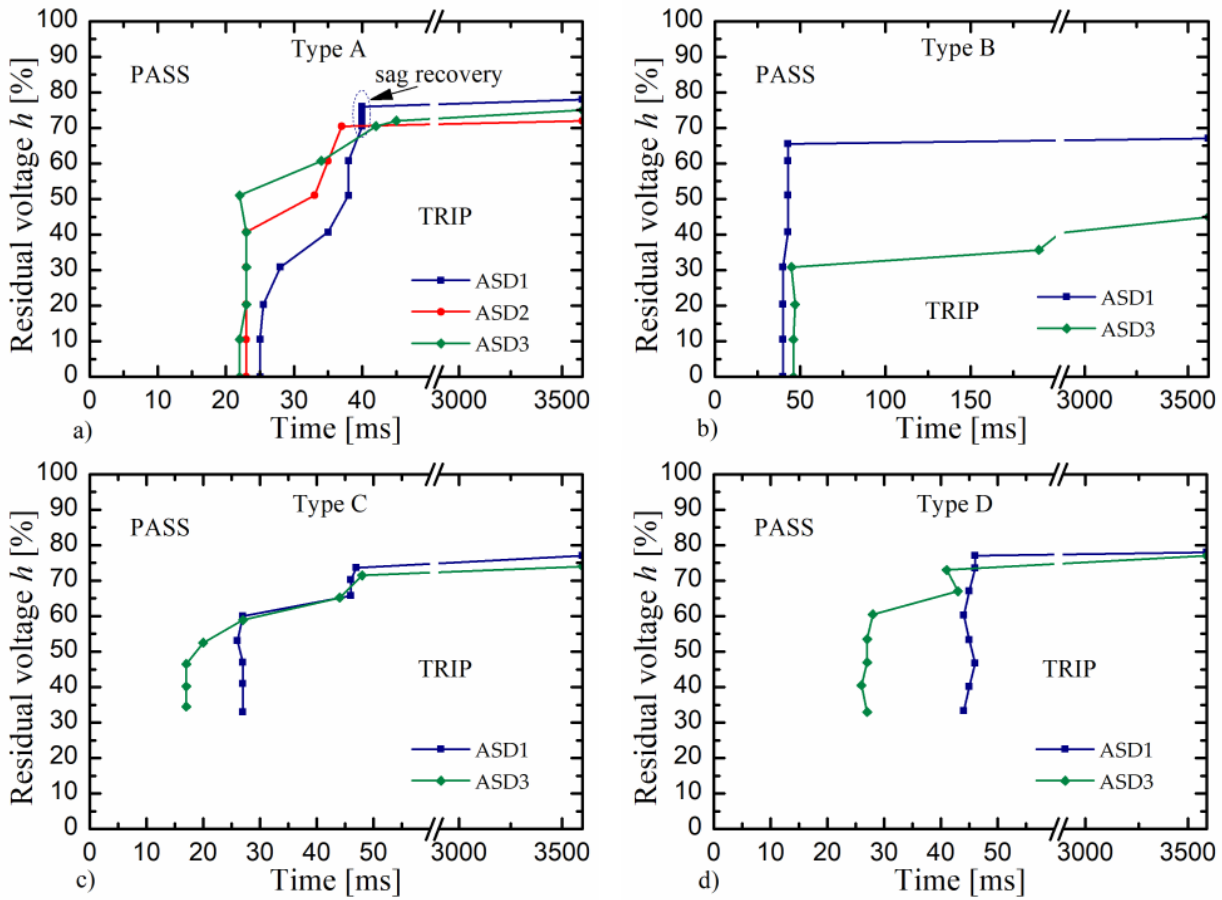

Fig. 6 Comparisons of voltage sags sensitivity under rated load and speed

In the case of type B sags, sensitivity differences are more significant. The comparative tests results for this type of sags are shown in Figure 6b. Namely, ASD1 converter is sensitive to all sags in which the residual voltage is less than $65 \%$ wherein the disconnection occurs due to the action of under-voltage protection. When the threephase reactor $3 \times 1.4 \mathrm{mH}$ is added at the converter input, insensitivity to this type of sags has been achieved. In case of ASD2 converter with integrated choke in the DC circuit, complete insensitivity for this type of sags is determined. In conjunction with the effects of these sags, ASD3 converter shows significant differences comparing to the other two. In fact, the significant divergence of the test results for a given value of $h$ are observed with this converter, which is probably due to the influence of point on wave when sag initiated. Due to the limitations of test equipment this effect could not be fully explored and confirmed. Figure $6 \mathrm{~b}$ shows the points corresponding to the lowest turn off values obtained in the experiments.

The obtained experimental results for type $\mathrm{C}$ sags are shown in Figure 6c. For power outages within the range of $33.3 \% \leq h \leq 60 \%$, the disconnection of ASD1 converter occurs in around $27 \mathrm{~ms}$, while for higher values of $h$, the shutdown occurs in $47 \mathrm{~ms}$. If the value of residual voltage $h$ is above $73.6 \%$, this converter does not show sensitivity to this type of sags. The converter ASD2 did not turn-off during that sag, but it showed significant speed deviation. The corresponding results and comments will be given later. ASD3 converter is the most sensitive to this type of sags, and at low values of $h$ the shutdown occurs in $17 \mathrm{~ms}$, while at higher values of $h$ behavior of this converter is similar to the first one. 
Considering the impact of type D sags, ASD1 behaves similarly to the case of type B, which can be seen in Figure 6d. Converter ASD2 is completely insensitive to this type of sags. The converter ASD3 is the most sensitive to this type of sags with a shutdown time of about $25 \mathrm{~ms}$ for lower values of $h$, while for higher values of residual voltage the switch-off time is about $45 \mathrm{~ms}$. For values of $h>76 \%$, ASD1 and ASD3 converters become insensitive for this type of sags.

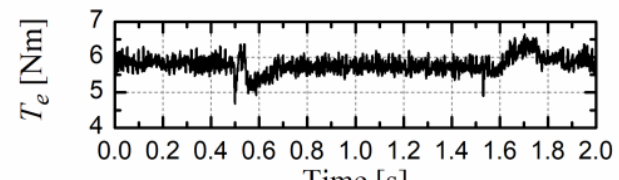

Time $[\mathrm{s}]$
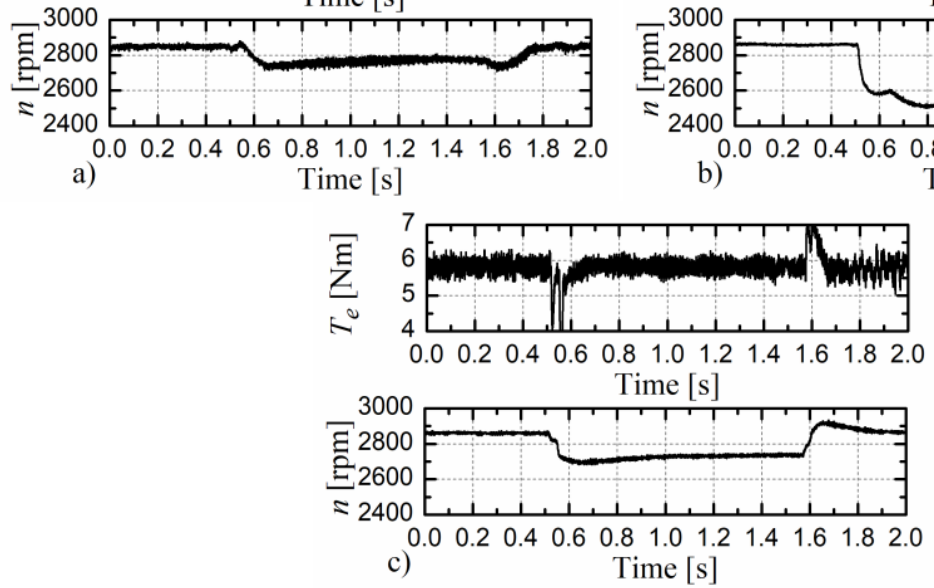

Fig. 7 Responses of ASDs for symmetrical sag with $h=80 \%$ :

a) ASD1; b) ASD2; c) ASD3

Fig. 6a shows that all converters overcome the type A sags with $h \geq 80 \%$ without interruption, but there is no insight of possible performance degradation. To illustrate potential problems for the users, identical experiments were conducted - three-phase symmetrical voltage sags with $h=80 \%$ and duration $\Delta t=1 \mathrm{~s}$ was initiated at the input of a nominally loaded drive with a reactive load characteristic. The time diagrams of the estimated torque and speed for the specified ASDs are shown comparatively in Figs. 7ac. It can be seen that there is a drop in speed during sag due to the limitation of the available IM torque. It should be noted that the figures show the estimated torques, so it is obvious that the torque estimation is not correct during the sags of ASD2 converter. Namely, the estimated torque shows an increase during sags, and the speed decreases. There are significant differences in speed reduction - the highest speed reduction is obtained by ASD2 converter, while the least speed reduction is in case of ASD1 converter. In addition to the voltage sag immunity, a drop in speed during these power quality events may be of crucial importance for the potential users. 

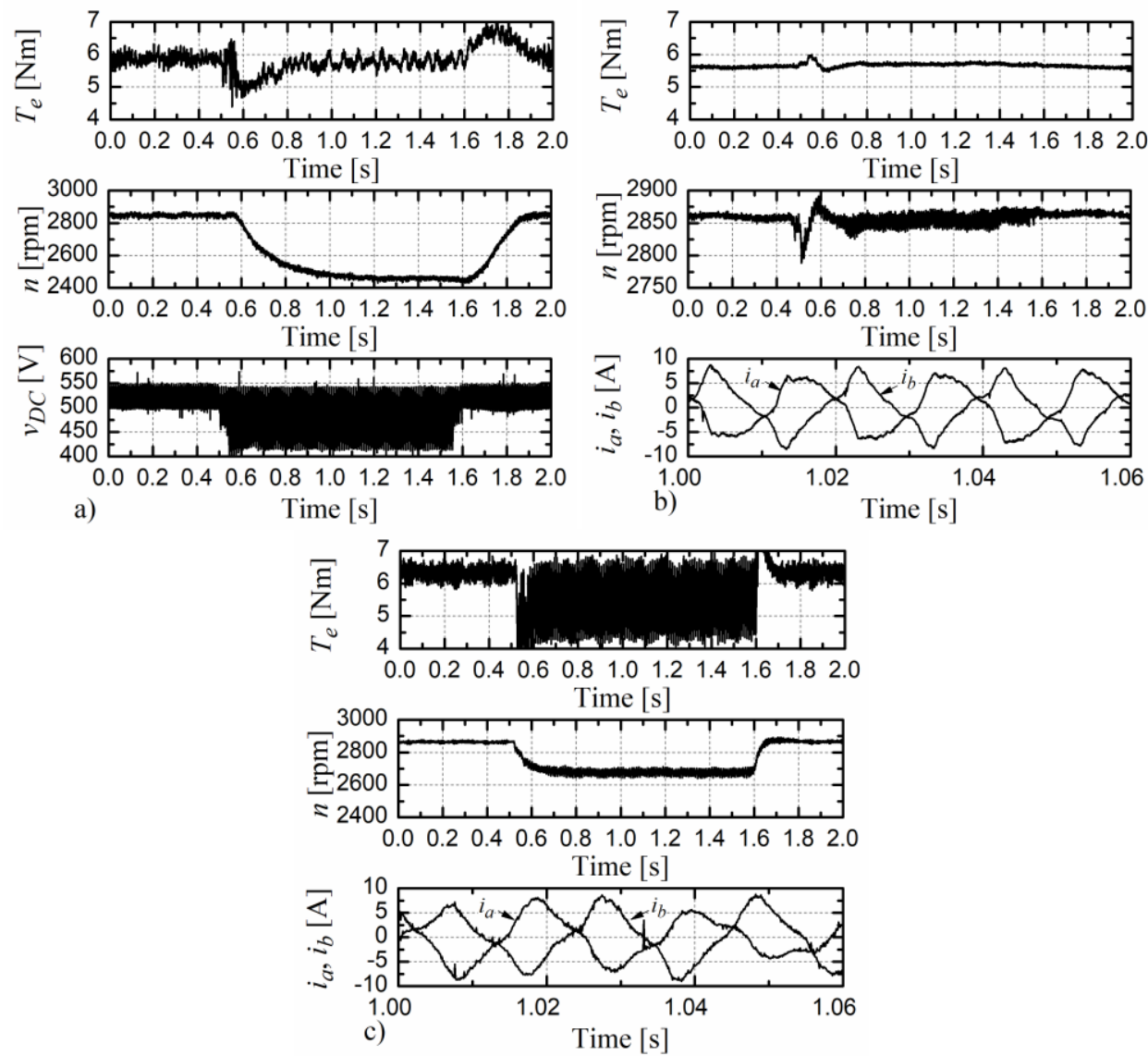

Fig. 8 Single-phase sag type B responses: a) ASD1; b) ASD2; c) ASD3

When the single-phase voltage sag is imposed on ASDs input terminals, and the converter maintains operation, there are significant differences in performance in terms of IM torque and speed during sag. Experimental results for this sag type are shown in Figs. 8a-c. As a representative example, value $h=70 \%$ is selected for which ASD1 converter overrides under-voltage limit, but the main consequence is a significant speed deviation. This is due to the fact that in this case the mean value of DC voltage is reduced, as shown in Fig. 8a (direct measurement of DC link voltage of converter ASD1 is possible).

As already mentioned, the converter ASD2 is not sensitive to this sag type. The drive response to this disturbance is shown in Fig. $8 \mathrm{~b}$ with $h=0 \%$ for remaining voltage in phase A. It can be noticed that there is torque deviation only in the transient, when the voltage sag is initiated. As for speed, there is no static error during sag, but a noticeable increase in ripple is evident. This is definitely a consequence of the increased torque oscillations (not visible at the estimated torque) caused by the deformations of the stator current, as shown in the bottom sub-figure in Fig. 8b. ASD3 converter response is shown in Fig. 8c for B-sag with $h=50 \%$. Here, a significant drop in speed is notable, aside from the motor torque and currents ripples increase. Finally, the conclusion with respect to B- 
sag is that there is a diversified drive response, where the primary reason is the DC circuit configuration - the converter with the complete LC filter shows the insensitivity to this sag in terms of torque/speed deviation.

As mentioned above, ASD2 converter is insensitive to type $\mathrm{C}$ sags, but not without consequences on the IM torque and speed. The speed responses during 1s voltage sag with different values of $h$ are shown in Fig 9a. It is noticeable that the applied voltages lead to the torque limitation that is manifested in terms of speed reduction, as expected according to Fig. 4. For this converter, type $\mathrm{C}$ sags with residual voltage greater than $80 \%$ are overcome without visible consequences on speed deviation. Finally, as an illustration of the performance deviation from the declared ones, ASD1 and ASD3 responses for type $\mathrm{C}$ sags with residual voltage $h=80 \%$ are shown in Figure 9b. Also, voltage limitation as well as the inability of speed control without a static error is visible.
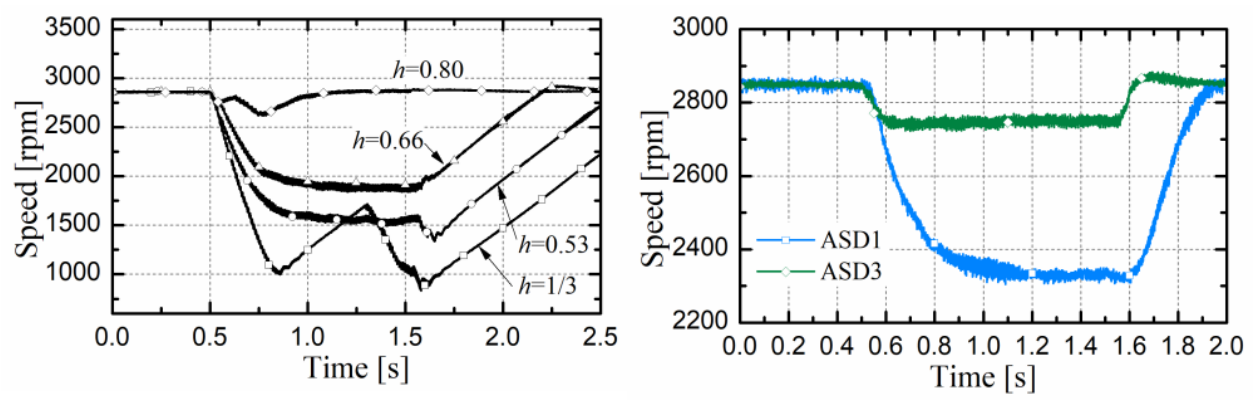

Fig. 9 ASD2 speed deviation for type C sag in function of residual voltage (left); ASD1 and ADS3 speed deviation for $h=80 \%$ (right)

\section{CONCLUSION}

Operation of vector controlled IM drives can be affected by voltage sags resulting in operation failure or in torque and speed deviation. This cannot be accepted for highperformance applications. This paper analyzes the behavior of three RFO controlled ASDs in application with IM. Previous studies paid attention to general purpose ASDs, mainly with scalar control. Testing of RFO controlled ASDs is more sophisticated and demanding task, taking into account necessity to adjust the drive control parameters and error handling. According to the detailed investigation, we conclude that the obtained test results can be significant for end-users of high-performance ASDs, since the experiments show that there are significant deviations in the performance during sags.

Reduction of the available motor torque and consequently drop in the speed have been described analytically and experimentally confirmed. This effect is the most important in explaining the experimental results and in proposing override algorithms. Considering converters topology, the main conclusion recommends a DC choke installation in order to increase the voltage sag immunity. A side effect of this improvement is suppression of the voltage drop in the DC-link voltage that acts as a key factor for the available torque limitation. Future studies will be focused on software modification possibilities of industrial devices, in order to overcome the limitations imposed by sags. 
Acknowledgement: This work was supported in part by Project Grant III 44006 financed by the Ministry of Education, Science and Technological Development of the Republic of Serbia within the framework of integrated and interdisciplinary research for the period 2011-2017.

\section{REFERENCES}

[1] M. H. Bollen, I. Gu, Signal Processing of Power Quality Disturbances, Wiley-IEEE Press: Hoboken, NJ, USA, 2006.

[2] Electromagnetic compatibility (EMC), Part 4: Testing and measurement techniques, Section 34: Voltage dips, short interruptions and voltage variations immunity tests for equipment with mains current more than 16 A per phase, IEC 61000-4-34:2005+A1:2009, International Electro-technical Commission, 2009.

[3] Electromagnetic compatibility (EMC), Part 4: Testing and measurement techniques, Section 11: Voltage dips, short interruptions and voltage variations immunity tests, IEC Standard 61000-4-11, International Electro-technical Commission, March 2004.

[4] S. Z. Djokic, K. Stockman, J. V. Milanovic, J. J. M. Desmet, R. Belmans, "Sensitivity of AC adjustable speed drives to voltage sags and short interruptions," IEEE Transaction on Power Delivery, vol. 20, no. 1, pp. 494-505, 2005. [Online]. Available: http://dx.doi.org/10.1109/TPWRD.2004.832353

[5] M. Petronijevic, B. Veselic, N. Mitrovic, V. Kostic, B. Jeftenic, "Comparative study of unsymmetrical voltage sag effects on adjustable speed induction motor drives," IET Electric Power Applications, vol. 5, no. 5, pp. 432-442, 2011. [Online]. Available: http://dx.doi.org/10.1049/iet-epa.2010.0144.

[6] K. Lee, T. M. Jahns, W. E. Berkopec, T. A. Lipo, "Closed-form analysis of adjustable-speed drive performance under input-voltage unbalance and sag conditions," IEEE Transaction on Industry Applications, vol. 42, no. 3, pp. 733-741, 2006. [Online]. Available: http://dx.doi.org/10.1109/TIA.2006.872953.

[7] K. Stockman, F. D' hulster, J. Desmet, R. J. M. Belmans, "Torque behaviour of a RFO induction motor drive under voltage sag conditions," in Proceedings of 10th International Conference on Harmonics and Quality of Power ICHQP 2002, Rio de Janeiro, Brazil, pp. 359-364, vol. 2002. [Online]. Available: http://dx.doi.org/10.1109/ICHQP.2002.1221460

[8] M. Petronijević, N. Mitrović, V. Kostić, B. Banković, "An Improved Scheme for Voltage Sag Override in Direct Torque Controlled Induction Motor Drives," Energies, vol. 10, no. 5, pp. 663, 2017. [Online]. Available: http://dx.doi.org/10.3390/en10050663

[9] S. C. Vegunta, J. V. Milanović, S. Ž. Djokić, "Modelling of V-Hz and vector controlled ASDs in PSCAD/EMTDC for voltage sag studies." Electric Power Systems Research, vol. 80, no. 1, pp. 1-8, 2010. [Online]. Available: https://doi.org/10.1016/j.epsr.2009.07.015

[10] S. Bogarra, L. Monjo, J. Saura, F. Córcoles, J. Pedra, "Comparison of simplified models for voltagesource-inverter-fed adjustable-speed drive during voltage sags when the during-event continue mode of operation is active," IET Electric Power Applications, vol. 8, no. 9, pp. 329-341. [Online]. Available: http://dx.doi.org/10.1049/iet-epa.2013.0323

[11] International Electro-technical Commission: 'Electromagnetic Compatibility (EMC), Part 4: Testing and Measurement Techniques, Section 30: Power Quality Measurement Techniques'. IEC Standard 61000-4-30, 2003.

[12] IEEE Recommended Practice for Monitoring Electric Power Quality, IEEE Std. 1159-1995, 2009

[13] M. Bollen, M. Stephens, S. Djokic, K. Stockman, B. Brumsickle, J. Milanovic, J. R. Gordón, R. Neumann, G. Ethier, F. Corcoles, A. Ferguson, P. Goossens, P. Ligot, A. L. Leiria, P. Marteyn, A. McEachern, J. Mentzer, I. McMichael, U. Minnaar, K. van Reusel, F. Zavoda, "Voltage dip immunity of equipment and installations," CIGRE/CIRED/UIE Joint Working Group C4.110, pp. 1-279, Apr. 2010.

[14] S. Arias-Guzman, O. A. Ruiz-Guzman, L. F. Garcia-Arias, M. Jaramillo-Gonzales, P. D. CardonaOrozco, A. J. Ustariz-Farfan, E. A.Cano-Plata, A. F. Salazar-Jimenez, "Analysis of Voltage Sag Severity Case Study in an Industrial Circuit," IEEE Transaction on Industry Applications, vol, 53, no. 1, pp. 1521, 2017. [Online]. Available: 10.1109/TIA.2016.2603470

[15] S. Rinaldi, D. D. Giustina, P. Ferrari, A. Flammini, "Distributed monitoring system for voltage dip classification over distribution grid," Sustainable Energy, Grids and Networks, vol. 6, pp. 70-80, 2016. [Online]. Available: https://doi.org/10.1016/j.segan.2016.02.004

[16] A. dos Santos, M. T. C. de Barros, "Voltage sags tolerance and responsibility curves," in Proceedings of IEEE Eindhoven PowerTech 2015, Eindhoven, Holland, 2015, pp. 1-6.

[17] T. Wymann, P. Jörg, "Power loss ride-through in a variable speed drive system," in Proceedings of Petroleum and Chemical Industry Conference Europe PCIC 2014, Amsterdam, Holland, 2014, pp. 1-9. 
Voltage Sag Sensitivity of Industrial Vector Controlled Induction Motor Drives - A Comparative Study 183

[18] Y. Yang, F. Blaabjerg, Z. Zou, "Benchmarking of Voltage Sag Generators," in Proceedings of the 38th Annual Conference of the IEEE Industrial Electronics Society, Montreal, Canada, 2012, pp. 943-948.

[19] Siemens, "Sinamics S120 function manual drive functions," User`s manual, 07/2016. [Online]. Available: https://support.industry.siemens.com

[20] Danfoss, "Programming Guide VLT AutomationDrive FC301/302," User`s manual, 2017. [Online]. Available: http://drives.danfoss.com

[21] Schneider Electric "Altivar 71 Variable speed drives for asynchronous motors," User`s manual, 2006. [Online]. Available: http://www2.schneider-electric.com 